\title{
Bacterial isolates from swab specimens and their susceptibilities to antibacterial agents in Maiduguri Metropolitan City, Nigeria
}

\author{
John David OHIEKU ${ }^{1}$, Miriam Ifeoma NNOLIM ${ }^{1}$ and Bala Galadima GADZAMA ${ }^{2}$ \\ ${ }^{I}$ Department of Clinical Pharmacy and Pharmacy Administration, Faculty of Pharmacy, University of \\ Maiduguri, P.M.B. 1069, Maiduguri, Borno State, Nigeria. \\ ${ }^{2}$ Department of Microbiology and Parasitology, University of Maiduguri Teaching Hospital, Maiduguri, \\ Borno State, Nigeria. \\ ${ }^{*}$ Corresponding author; E-mail: joni.dav@hotmail.co.uk
}

\begin{abstract}
The aim is to assess pathogenic bacteria from infectious swab sites and determine variation in their susceptibility and resistance to commonly utilized antibacterial agents as well as their multi-drug resistance patterns. 385 pathogenic bacteria from clinical swab specimens of ear, wounds, abscesses, eye discharges, diabetic foot ulcers, urethra and high vaginal swabs were isolated through agar culture and investigated for susceptibilities status. Staphylococcus aureus isolates accounted for 50.6\%. Pathogens like Escherichia coli (17.4\%), Klebsiella spp (11.4\%), Pseudomonas spp (9.9\%), Proteus spp (9.4\%) and Alpha-haemolytic streptococci (1.3\%) were similarly isolated. Pseudomonas spp, Klebsiella spp and E. coli showed total resistance to nalidixic acid but Staphylococcus aureus recorded partial resistance with all antibacterial agents. The activities of ciprofloxacin against Pseudomonas spp was better than other fluoroquinolones such that significant difference exists $(\mathrm{P}<0.05)$ when compared with pefloxacin. The activities of gentamicin against Klebsiella spp appeared not superior to streptomycin. Ciprofloxacin and ofloxacin showed uniform activities against Proteus spp, which showed partial resistance to all agents except sparfloxacin. Multi-drugs resistances are high with all organisms. Many pathogens cause infections in swab sites. The knowledge of causative organisms and their sensitivities are important since multi-drug- resistant organisms are widespread, thus making empirical choice difficult.
\end{abstract}

(c) 2010 International Formulae Group. All rights reserved.

Keywords: Bacterial isolates, Swab Specimens, Susceptibilities, Antibacterial Agents, Maiduguri Metropolitan City.

\section{INTRODUCTION}

The exploitation of micro-organisms and their products by man for several beneficial purposes are well recognized (Jonkers et al., 2009; Wassenaar, 2009). For instance, they find applications in the field of food industries and are used for the control of insect pests, production of vaccines and antibiotics, as recombinant DNA in biotechnology industries, construction and so on (Russell, 2004; Jonkers et al., 2009; Wassenaar, 2009). Despite these applications, micro-organisms particularly bacteria constitute menace to man since they are responsible for several diseases capable of terminating man's life (Collazos, 2002). 
We have always been faced with the challenge to eradicate the pathogenic ones with antimicrobial agents since several adaptive measures are developed by microbes to evade the effects of antimicrobial agents (McManus, 1997; Anthony et al., 2002). They may cause resistance by deactivating the chemical agents and interference with nucleic acid synthesis, binding to ribosomes, inhibition of cell wall synthesis and folate metabolism, mutation and acquisition of new DNA by bacteria, alteration of drug target sites, bypassing drug metabolism and so on (McManus, 1997). Despite several improvements to sustain antimicrobial activities against pathogenic bacteria, their resistance to multiple drugs still thrive and constitute major problem in health care system (Karen, 2004), which have always justify the need for the search for new, effective and safe agents in order to resolve resistance problems.

The clinical outcomes of these effects are treatment failures, increased hospitalization and stay on health care facilities, and economic loss in terms of wages (Patrick et al., 2010). All these are putting the survival of human race at great risk. This work is the assessment of sensitivity and resistant status of bacteria isolated from swab specimens to antibacterial agents and is intended to serve useful information to clinicians and health personnel in the studied zone.

\section{MATERIALS AND METHODS}

Clinical swab specimens consisting of 150 males and 235 females obtained from the ears, wounds, eye discharges, diabetic foot ulcers, urethra and high vaginal swabs were investigated for pathogenic bacteria in 2006 at Maiduguri Metropolitan City. The specimens were processed by performing Gram stain from the direct smear. Nutrient Agar and Macconkey Agar media were used to culture and isolate pathogens after inoculation and incubation at $37{ }^{\circ} \mathrm{C}$ for 48 hours. Conventional biochemical tests were used to confirm bacterial isolates. Susceptibility tests were performed using the disc diffusion techniques and tested against the disc concentrations of ciprofloxacin $(30 \mu \mathrm{g})$, streptomycin $(30 \mu \mathrm{g})$, pefloxacin $(10 \mu \mathrm{g})$, cotrimoxazole $(30 \mu \mathrm{g})$, ampicillin $(30 \mu \mathrm{g})$, ofloxacin $(10 \mu \mathrm{g})$, gentamicin $(10 \mu \mathrm{g})$, nalidixic acid $(30 \mu \mathrm{g})$, amoxicillin/clavulanic acid $(30 \mu \mathrm{g})$, rifampicin $(10 \mu \mathrm{g})$, chloramphenicol $(20 \mu \mathrm{g})$, erythromycin (30 $\mu \mathrm{g})$, norfloxacin $(30 \quad \mu \mathrm{g}) \quad$ and ampicillin/cloxacillin (30 $\mu \mathrm{g})$. Multi-drugresistant cases are defined as resistance of isolated pathogens to antibiotics from at least three different classes.

\section{Statistical analysis}

Chi Square Tests were used to determine levels of significant differences between the activities of two or more agents.

\section{RESULTS AND DISCUSSION}

Assessing pathogenic bacteria from infectious sites is made possible through swab specimen collections since the procedure is simple with no associated health or safety risks (Higgins, 2008). The summary of various pathogenic bacteria isolated from swab specimens is as shown in Table 1. Staphylococcus aureus was the predominant pathogen accounting for $50.6 \%$ of the total bacterial isolates since the pathogen is ubiquitous and widely implicated in varieties of conditions including urinary tract infections (UTI) and skin and soft tissues infections (Nick, 2001) from where these swab specimens are obtained. This result is similar to the work of Adedeji et al. (2007) in southwest Nigeria, where Staphylococcus aureus was similarly reported as the major pathogen in urine and wound swabs, though Pseudomonas spp was the predominant isolates in their ear swabs. The slight difference is naturally due to geographical factors and variation in the study period.

The coliforms bacteria like Escherichia coli $(17.4 \%)$, Klebsiella spp (11.4\%), and Proteus spp $(9.4 \%)$ were similarly isolated 
particularly from the ear and high vagina swab specimens of patients who presented with otitis media and urinary tract infections, respectively but Alpha-haemolytic streptococci were the least isolated agents (1.3\%) while Pseudomonas spp isolation was $9.9 \%$ (Table 1). These bacterial isolates are not in contrast with the works of other researchers (Brown and Izundu, 2004; Okon et al., 2004; Okesola and Makanjuola, 2009; Alsaimary et al., 2010) but their proportions vary due to geographical or environmental factors.

The gender distribution of isolated pathogens (Table 2) showed 39\% bacterial isolates in male compared to $61 \%$ proportion in female. Gram positive bacteria accounted for $37.5 \%$ and $62.5 \%$ pathogens in male and female specimens respectively. Among the Gram negative isolates, Escherichia coli, Klebsiella spp and Pseudomonas spp were similarly higher in the female than the male. Only Proteus spp recorded higher incidence in male $(63.9 \%)$ than female $(36.1 \%)$. In all, $40.5 \%$ and $59.5 \%$ Gram negative pathogenic bacteria were isolated in male and female respectively. The incidence of Gram positive organisms was slightly higher than that of the Gram negative (51.9\% versus $48.1 \%$ ). Our results demonstrated that gender variations may contribute to the risk factors influencing infection in some swab specimens, particularly in those obtained from urogenital areas.

The in vitro sensitivity of Staphylococcus aureus indicated partial resistance to all the tested agents though at varying degrees (Figure 1). High resistance rates were recorded with the penicillins particularly ampicillin (83\%), ampicillin/ cloxacillin (81\%) and flucloxacillin (84\%). These resistance patterns are not surprising since they are easily aided through antibiotic misuse and because the organism produces enzymes that deactivate many penicillins (Herzberg and Moult, 1987). In the UK, only $2 \%$ of $S$. aureus isolates are sensitive to penicillins (Wikipedia, 2010). Resistance of
Staphylococcus aureus was first reported in the early 1940's followed by rapid rise in resistance trends in many regions (Franklin, 2003). Cotrimoxazole and nalidixic acid similarly showed high resistance rates (being $87 \%$ and $92 \%$ respectively) possibly due to their past misuse or overuse (Goossens et al., 2005). The sensitivity result for cotrimoxazole is higher than reported in South-eastern Nigeria, but that of ampicillin is almost similar (Ikeagwu et al., 2008) while higher resistance rates are reported in other regions (Chigbu and Ezeronye, 2003). The empiric use of these agents should therefore be avoided. However, clavulanic acid in amoxicillin leading to the inhibition of the $\beta$ lactamase enzymatic activities of Staphylococcus aureus (Kar, 1996) made significant impact $\left(\mathrm{X}^{2}=13.77, \mathrm{P}<0.005\right)$ in its sensitivity pattern over the other penicillins lacking such combination.

The activities of the fluoroquinolones against Staphylococcus aureus range between 88-97\% except in norfloxacin whose low invitro activities $(36 \%)$ indicated significant difference $\quad\left(X^{2}=201.28, \quad P<0.005\right)$ when compared with the rest fluoroquinolones. Although these activities are higher than recorded in South-eastern Nigeria (Ikeagwu et al., 2008), it is still necessary to regulate their indiscriminate uses in order to sustain their relevance in chemotherapy. The activities of gentamicin (53\%), lincomycin (55\%) and erythromycin (52\%) against Staphylococcus aureus were just slightly above the average. $177(90.8 \%)$ cases of multi-drug-resistant Staphylococcus aureus were encountered during the study (Table 3). Multi-drugresistant Staphylococcus aureus reported elsewhere in other regions (Voss and Doebbelling, 1995), but cases in this study zone are much higher than recorded in the United States (Styer et al., 2006). Poor compliance with antibiotic policy may account for the differences.

The in-vitro sensitivity and resistance of Pseudomonas spp to antibacterial agents is as shown in Figure 2. The total resistance 
recorded with co-trimoxazole, nalidixic acid and cefuroxime is in contrast to similar study reported in Jamaica (Brown and Izundu, 2004) possibly because of past overuse of agents and poor control measures. It is also a common practice for patient to misuse several agents before seeking medical interventions from practitioners. However, high resistance rates were observed with all other agents including some fluoroquinolones with ciprofloxacin indicating high activities $(97 \%)$ that were significantly different $\left(\mathrm{X}^{2}=15.68, \mathrm{P}<0.005\right)$ from ofloxacin $(70 \%)$ and pefloxacin $(59 \%)$ as well as sparfloxacin $(\mathrm{P}<0.050)$. These results are remarkably higher than previously reported for these drugs against this pathogen in the region (Okon et al., 2004) indicating that there is an improvement over their past irrational utilization, but sparfloxacin is no longer the most active agent against Pseudomonas spp in the region as previously reported (Okon et al., 2004) due to its increased usage. The aminoglycoside gentamicin and streptomycin appeared to have uniform activities (Figure 2) and have similarly shown improved activities than previously reported in the zone (Okon et al., 2004). The recorded higher activities over their previous status is not because of antibiotic usage policy but is attributable to increased use of newer agents, indicating that proper antibiotic usage policy can resolve the high rate of resistance problems in the region.

Multi-drug-resistant Pseudomonas spp $(94.7 \%)$ are recorded in (Table 3), making it one of the highest in this study. Pseudomonas spp are similarly reported to show multi-drugresistant cases elsewhere in the world (Marelee et al., 2005) since several mechanisms including those of acquired $\beta$ lactamase resistance, $\beta$-lactamase production, upregulation of efflux systems and decreased outer membrane permeability are reported as ways some Pseudomonas spp can cause multidrug resistance (Livermore, 2002). With ciprofloxacin serving as one of the most frequently used empiric agents in the region, our study has not found significant resistance risk associated with the agent against Pseudomonas spp isolated from swab sites.

The in-vitro antibacterial activities against Proteus spp isolates are as shown in Figure 3. The results indicated partial resistance to all the agents except sparfloxacin. The activities of the fluoroquinolones against Proteus spp range between $69 \%$ in pefloxacin to $100 \%$ in sparfloxacin. A significant difference exist $\left(\mathrm{X}^{2}=4.76, \mathrm{P}<0.05\right)$ when the activities of sparfloxacin was compared with that of pefloxacin but uniform activities were recorded between ofloxacin and ciprofloxacin (91\% each). Resistance rates were high with ampicillin (97\%), co-trimoxazole (68\%), amoxicillin/clavulanic acid (84\%) and nalidixic acid (96\%) against the pathogen; therefore, their empiric choices should be avoided. These values are in contrast to the resistance values for ampicillin $(75 \%)$ and amoxicillin/clavulanic acid $(40 \%)$ reported in Basrah, Iraq (Alsaimary et al., 2010) but ciprofloxacin activity in this study $(91 \%)$ was higher than the $70 \%$ value reported for the same drug by Alsaimary et al. (2010).

The activities of ciprofloxacin (91\%), ceftriaxone $(75 \%)$ and amoxicillin/clavulanic acid $(16 \%)$ are better than the $33 \%, 50 \%$ and $0 \%$ respectively recorded with these drugs in South-west Nigeria (Okesola and Makanjuola, 2009). All the isolated Proteus spp are multidrug-resistant pathogens (Table 3) making it the highest in this study. Although multi-drugresistant Proteus spp are similarly reported elsewhere in the world (Reslinski et al., 2005), the fluoroquinolones are still the best treatment option in the zone but these results underscore the need for urgent antibiotic utilization policy in order to maintain the current effective ones.

The in vitro antibacterial activities against Escherichia coli isolates are as shown in Figure 4. Partial resistance to all the agents were observed except nalidixic acid which recorded total resistance. The incidence is 
however minimal with sparfloxacin (3\%) making it the most active agent in this study. The activities of streptomycin (66\%) and cefuroxime $(67 \%)$ were almost uniform. However, low sensitivities of the organism to the penicillins were indicated, particularly in ampicillin (2\%) and amoxicillin/clavulanic acid (14\%) compare to $40 \%$ and $80 \%$ respectively reported by Alsaimary et al. (2010) in Iraq. The activities of ciprofloxacin (72\%) and gentamicin (59\%) are similarly slightly lower than $80 \%$ each reported for both agents (Alsaimary et al., 2010) but higher than reported by Okesola and Makanjuola (2009) in Western Nigeria for ciprofloxacin $(62 \%)$, sparfloxacin (56.3\%), ceftriaxone $(62.3 \%)$ when compared with our study. Multi-drug resistant Escherichia coli are recorded in $91 \%$ cases (Table 3).

The in-vitro antibacterial activities against Klebsiella spp isolates are as shown in Figure 5. Partial resistance patterns similar to that of E. coli are observed with recorded high resistance rates with ampicillin (95\%), cotrimoxazole (92\%), amoxicillin/clavulanic acid $(71 \%)$. However, while sparfloxacin (88\%) and cefuroxime (57\%) were observed to indicate higher activities against $E$. coli than in Klebsiella spp, the reverse is the case with ciprofloxacin, pefloxacin and gentamicin. The differences in activities of agents against these two pathogens are not found to be significant but among the cephalosporins, the incidence of resistance by Klebsiella spp is lower in ceftriaxone (12.5\%) compared with cefuroxime $(43 \%)$. The recorded activities in this study are higher than those of Okesola and Makanjuola (2009) in western Nigeria. Multi-drug-resistant Klebsiella spp were recorded in $93.2 \%$ cases (Table 3).

The in-vitro antibacterial activities against $\alpha$-haemolytic streptococci isolates are as shown in Figure 6. The results indicated total resistance to ampicillin/cloxacillin, flucloxacillin and chloramphenicol while partial resistances were recorded with other agents except ciprofloxacin. Multi-drugresistant $\alpha$-haemolytic streptococci were recorded in $80 \%$ incidences (Table 3).

\section{Conclusion}

Many antibacterial agents particularly the older generation ones may have lost relevance in chemotherapy. Similarly, the high incidences of multi-drug-resistant isolated organisms occurring with several classes of antibacterial agents make their choices based on empirical consideration an uncertain venture. There is the urgent need to enhance efforts to conserve our current effective agents as well as to discover new efficacious antibiotics.

Table 1: Percentage distribution of isolated pathogens.

\begin{tabular}{|c|c|c|}
\hline Isolated pathogens & Nos isolated & Percentage $(\%)$ \\
\hline Staphylococcus auerus & 195 & $50.6 \%$ \\
\hline Escherichia coli & 67 & $17.4 \%$ \\
\hline Klebsiella spp & 44 & $11.4 \%$ \\
\hline Pseudomonas spp & 38 & $9.9 \%$ \\
\hline Proteus spp & 36 & 9.4 \\
\hline$\alpha$-haemolytic streptococci & 5 & $1.3 \%$ \\
\hline TOTAL & 385 & $100 \%$ \\
\hline
\end{tabular}


J. D. OHIEKU et al. / Int. J. Biol. Chem. Sci. 4(6): 2360-2370, 2010

Table 2: Gender distribution of pathogenic bacterial Isolates.

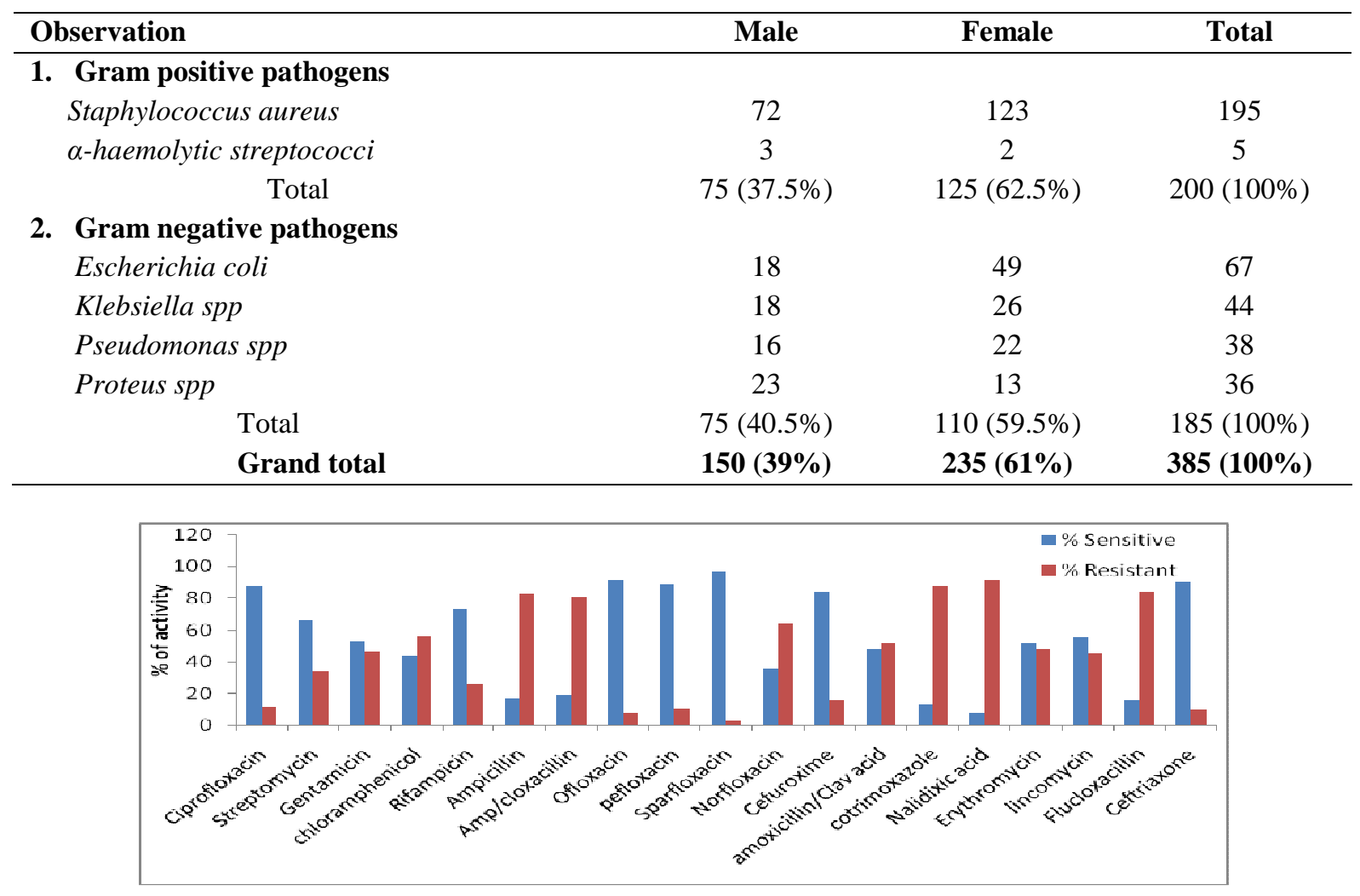

Figure 1: In-vitro antibacterial activities against Staphylococcus aureus. 
J. D. OHIEKU et al. / Int. J. Biol. Chem. Sci. 4(6): 2360-2370, 2010

Table 3: Bacterial Multi-Drug Resistance Pattern*.

\begin{tabular}{|c|c|c|c|c|c|c|c|c|c|c|}
\hline \multirow[t]{2}{*}{ Isolated pathogen } & \multirow[t]{2}{*}{ Total isolated } & \multicolumn{7}{|c|}{$\begin{array}{l}\text { Nos of classes of antibiotics to which pathogens showed } \\
\text { resistance (Multi-drug resistance (MDR) patterns) }\end{array}$} & \multirow[t]{2}{*}{$\begin{array}{c}\text { Total } \\
\text { MDR Bact. }\end{array}$} & \multirow{2}{*}{$\begin{array}{c}\% \\
\text { Multi-drug } \\
\text { resistance }\end{array}$} \\
\hline & & 1 & 2 & 3 & 4 & 5 & 6 & 7 & & \\
\hline Staph. aureus & 195 & 0 & 18 & 50 & 76 & 35 & 12 & 4 & 177 & $90.8 \%$ \\
\hline Pseudomonas spp & 38 & 0 & 2 & 8 & 14 & 12 & 2 & 0 & 36 & $94.7 \%$ \\
\hline E. coli & 67 & 0 & 5 & 16 & 28 & 17 & 0 & 0 & 61 & $91 \%$ \\
\hline Klebsiella spp & 44 & 0 & 3 & 7 & 24 & 7 & 3 & 0 & 41 & $93.2 \%$ \\
\hline Proteus spp & 36 & 0 & 0 & 11 & 17 & 8 & 0 & 0 & 36 & $100 \%$ \\
\hline$\alpha$-haem strepto cocci & 5 & 0 & 1 & 1 & 3 & 0 & 0 & 0 & 4 & $80 \%$ \\
\hline Total & 385 & NA & $\mathbf{N A}$ & 93 & 162 & 79 & 17 & 4 & 355 & $92.2 \%$ \\
\hline$\%$ & & & & $24.2 \%$ & $42.1 \%$ & $20.5 \%$ & $4.4 \%$ & $1 \%$ & $92.2 \%$ & \\
\hline
\end{tabular}

*Resistance to pathogen is defined as bacteria resistance to antibiotics from at least 3 different classes.

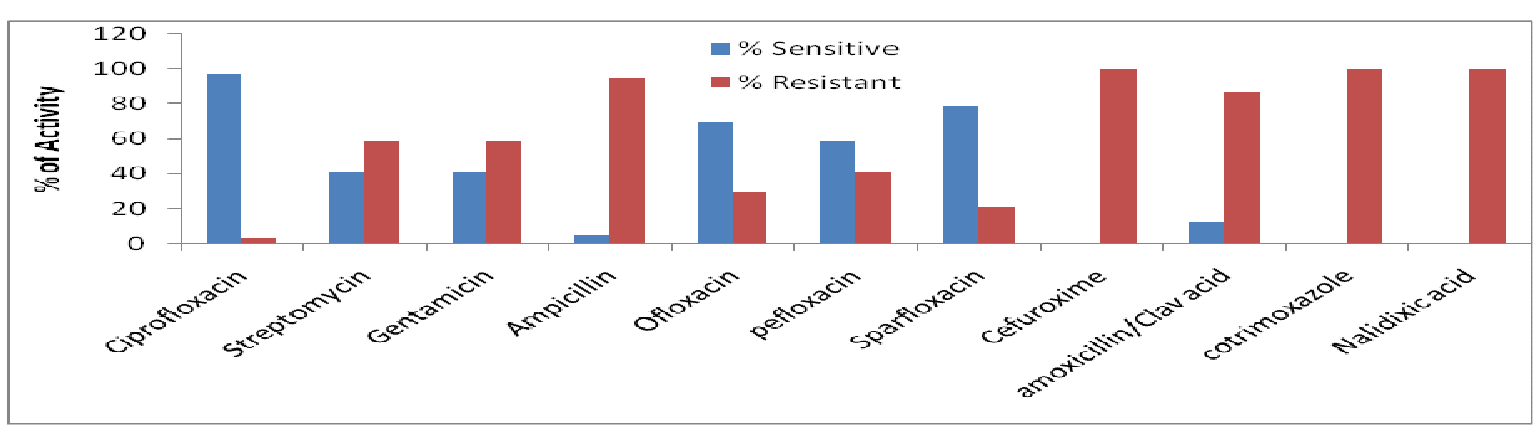

Figure 2: In-vitro antibacterial activities against Pseudomonas spp. 
J. D. OHIEKU et al. / Int. J. Biol. Chem. Sci. 4(6): 2360-2370, 2010

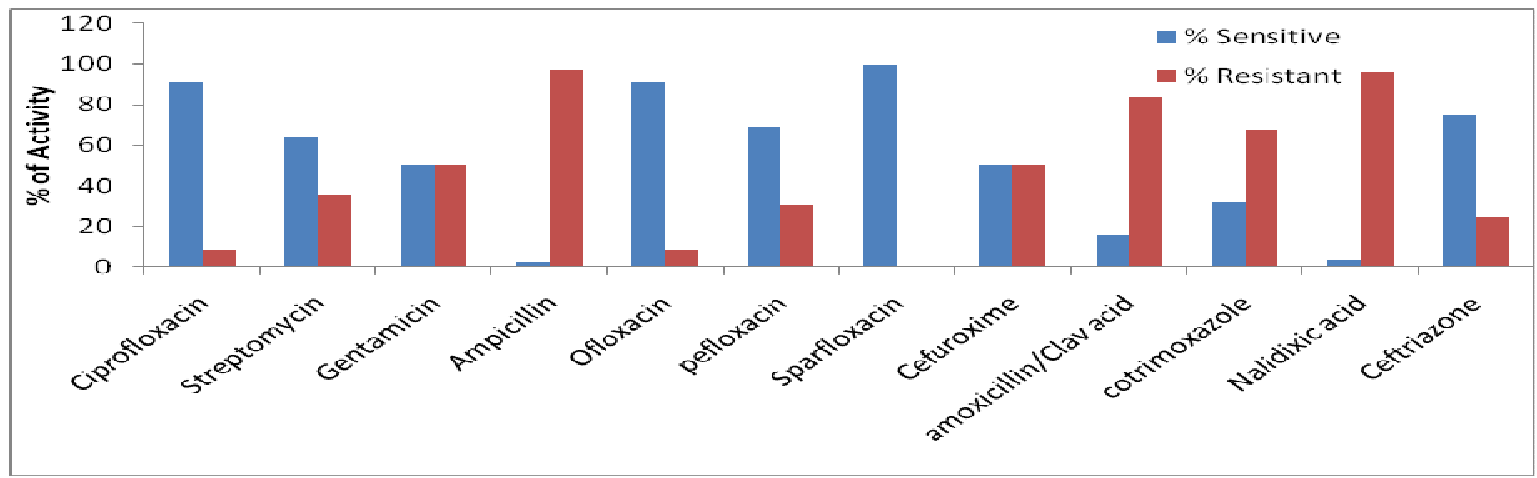

Figure 3: In-vitro antibacterial activities against Proteus spp.

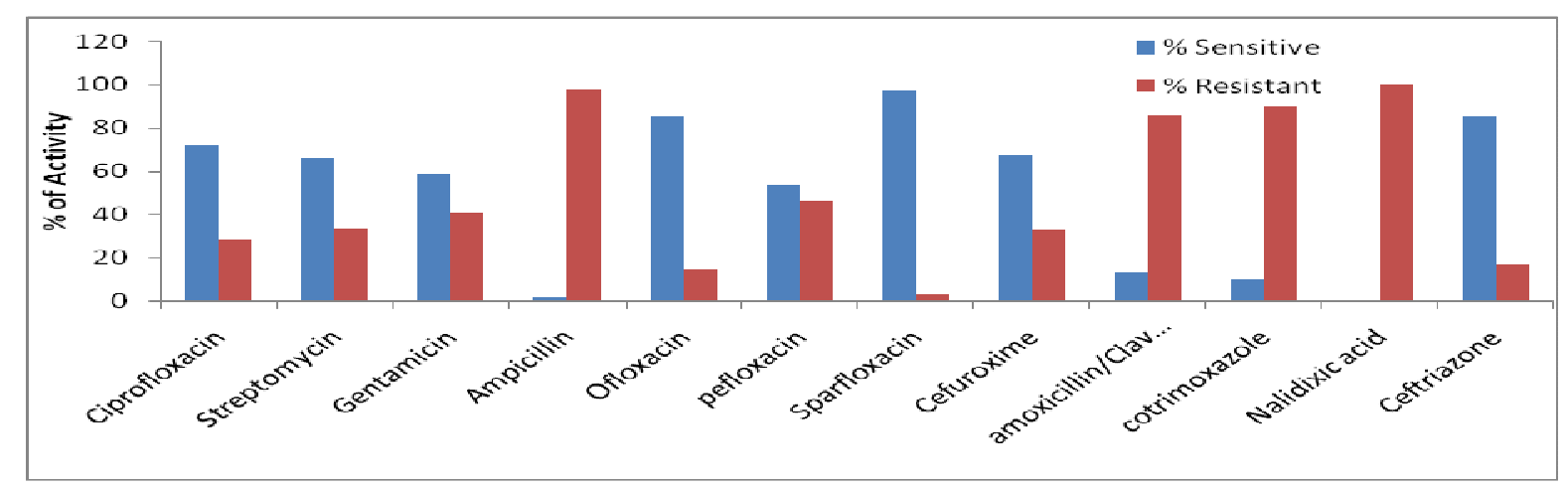

Figure 4: In-vitro antibacterial activities against Escherichia coli. 
J. D. OHIEKU et al. / Int. J. Biol. Chem. Sci. 4(6): 2360-2370, 2010

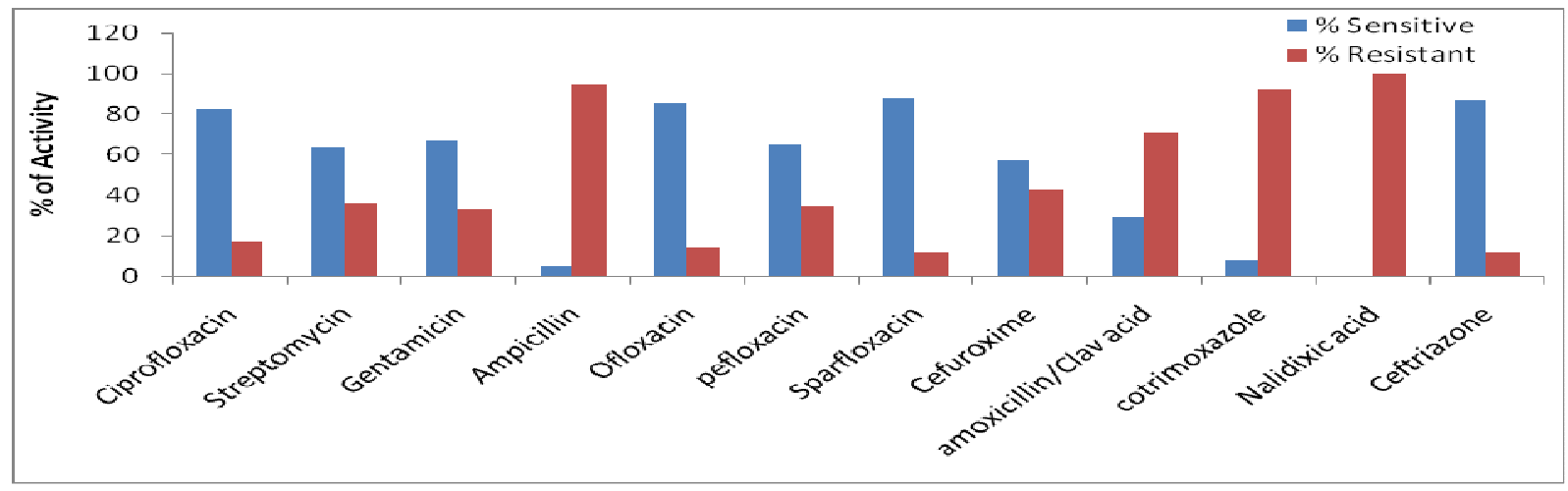

Figure 5: In-vitro antibacterial activities against Klebsiella spp.

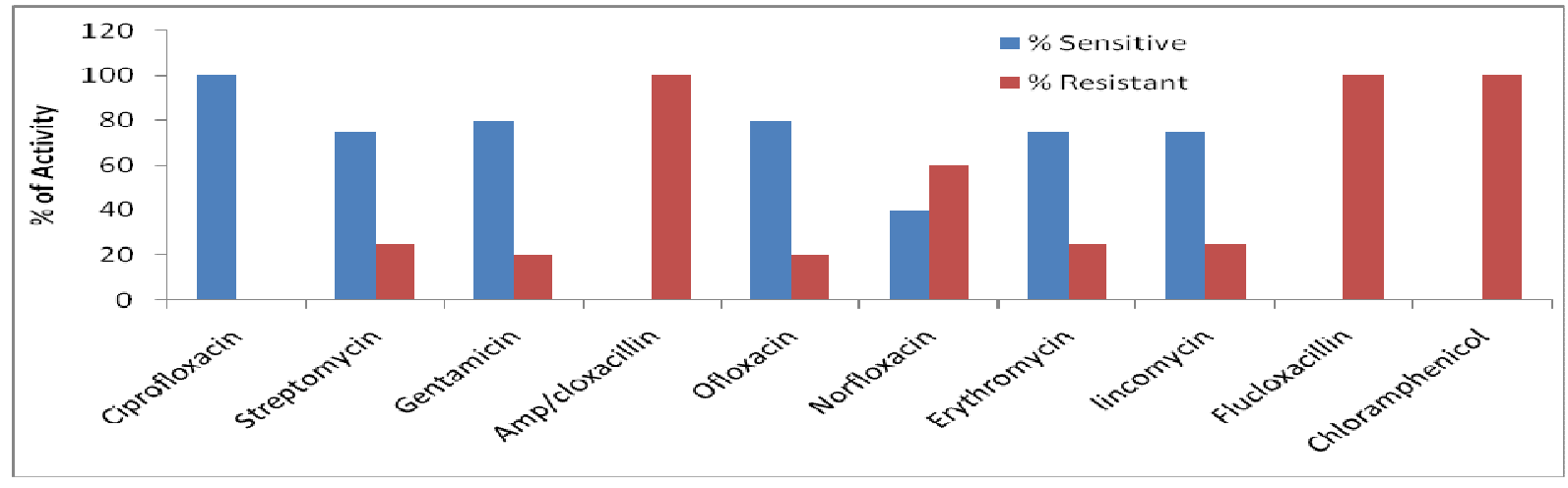

Figure 6: In-vitro antibacterial activities against $\alpha$-haemolytic streptococci. 


\section{ACKNOWLEDGEMENTS}

We want to gratefully acknowledge the support from the staff of Department of Microbiology, University of Maiduguri Teaching Hospital, Maiduguri.

\section{REFERENCES}

Adedeji GB, Fagade OE, Oyelade AA. 2007. Prevalence of Pseudomonas aeruginosa in clinical samples and its sensitivity to citrus extract. Afr J. Biomed Res., 10: 183-187.

Anthony C, Yanmin H, Richard B, Clive P. 2002. The future challenges facing the development of new antimicrobial drugs. Nature Reviews Discovery, 1: 895-910.

Asaimary IE, Alabassi AM, Najim JM. 2010. Impact of multi drugs resistant bacteria on pathogenesis of chronic supperative otitis media. Afr. J. Microbiol. Res., 4(13): 1373-1382.

Brown PD, Izundu A. 2004. Antibiotic Resistance in Clinical Isolates of Pseudomonas aeruginosa in Jamaica. Rev. Panam Salud Publica, 16(2): 125130.

Chigbu CO, Ezeronye OU. 2003. Antibiotic Resistant Staphylococcus aureus in Abia State of Nigeria. Afr J Biotech., 2(10): 374-378.

Collazos J. 2002. Secret agents: The menace of emerging infections. BMJ, 324: 49.

Franklin DL. 2003. Antimicrobial Resistance: An example of Staphylococcus aureus. J. Clin. Invest., 111(9): 1265-273.

Goossens H, Ferech M, Vander SR, Elseviers M. 2005. Out-patients antibiotic use in Europe and association with resistance: a cross-national database study. Lancet, 365(9459): 579-87.

Herzberg O, Moult J. 1987. Bacterial resistance to beta-lactam antibiotics: Crystal structute of beta-lactamase from Staphylococcus aureus $\mathrm{Pc} 1$ at $2.5 \mathrm{~A}$ resolution. Science, 236(4802): 694-701.

Higgins D. 2008. Specimens collection part 4 - obtaining a nasal swab. Nursing times.net http://www.nursingtimes.net/ specimencollection. Retrieved Dec. 2010.

Ikeagwu IJ, Amadi ES, Iroha IR. 2008. Antibiotic Sensitivity pattern to Staphylococcus aureus in Abakaliki, Nigeria. Pak. J. Med. Sci., 24(2): 231235.

John Heritage. 2006. What causes antibiotic resistance in bacteria? http://www.bmb. leeds.ac.uk/mbiology/ug/ugteach/icu8/ant ibiotics/resistance/resnotes.html Retrieved Dec 2010.

Kar PK. 1996. A combination of amoxicillin and clavulanic acid in the treatment of pyoderma in children. Indian $J$. Dermatology, Venereology and Leprology, 62(2): 91-94.

Jonkers HM, Thijssen A, Muyzer G, Copuroglu O, Schlangen E. 2009. Application of bacteria as self-healing agent for the development of sustainable concrete. Ecological Engineering 36(2): 230-235.

Karen B. 2004. Why it is important to continue antibacterial discovery. American Society for Microbiology. http://forms.asm.org/microbe. Retrived Dec 2010.

Livermore DS. 2002. Multiple mechanisms of antimicrobial resistance in Pseudomonas aeruginosa. Our worst nightmares. Clin Infect Dis. 34(5): 634-40.

Marilee DO, Douglas NF, Robert M, Rose J. 2005. Nosocomial infections due to multi-drugs resistant Pseudomonas aeruginosa: Epidemiology and Treatment Options. Pharmacotherapy, 25(10): 1353-1364.

McManus MC. 1997. Mechanism of microbial resistance to antimicrobial agents. Am J Health-system Pharmacy. 54(12): 14201433.

Nick D. 2001. Bacterial infection. Medicine. The Medicine Publishing Co Ltd. Pp 8487.

Okesola AO, makanjuola O. 2009. Resistance of third generation cephalosporins and other antibiotics by Enterbacteriaceae in 
Western Nigeria. Am J. Infect. Dis., 5(1): 17-20.

Okon KO, Agukwe PC, Oladosu W, Balogun ST, Uba. 2010. Antibiotic Resistance Pattern of Pseudomonas aeruginosa Isolated from Clinical Specimens in a Tertiary Hospital in North-eastern Nigeria. The Internet Journal of Microbiology, 6(2).

Patrick DM, Cassandra DS, Ida SH, Darshana TD, John TB. 2010. Attributable Hospital Costs and Length of Stay Associated with Health Care-Associated Infections Caused by Antibiotic-Resistant Gram Negative Bacteria. Antibiotic Agents and Chemotherapy, 54(1): 109-115.

Reslinski A, Gospodarek E, Mikucka A. 2005. Prevalence of multi-drugs resistant Proteus spp. Strains in clinical specimens and their susceptibility to antibiotics. Med. Dosw Mikrobiol., 57(2): 175-84.

Russell AD. 2004. Additional application of microorganisms in Pharmaceutical Sciences. In Hugo \& Russell's Pharmaceutical Microbiology $\left(7^{\text {th }}\right.$ edn). Stephen PD, Norman AH and Sean PG (eds). Blackwell Science; 441-457.
Saeed E, Abbas S, Alireza F. 2005. Quinolones: Recent structural and clinical developments. Indian J. Pharm. Research., 3: 123-136.

Styer D, Shehan DJ, Hogan P, Sahm DF. 2006. Laboratory-based surveillance of Current Resistance Pattens and Trends among Staphylococcus aureus: 2005 status in the United States. Ann Clin Antimicrob., 5: 2.

Wassenaar TM. 2009. Applied Bacteriology: use of bacteria in Industry. http://www.bacteriamuseum.org/cms/Bac teria/applied-bacteriology-use-ofbacteria-in-industry.html

Wikipedia, 2010. Staphylococcus aureus. http://en.wikipedia.org/wiki/Staphylococc us_aureus. Retrieved Dec. 2010.

Voss A, Doebbeling BN. 1995. Worldwide prevalence of methicillin resistant Staphylococcus aureus. Int. J. Antimicrob. Agents, 5: 101-106. 